
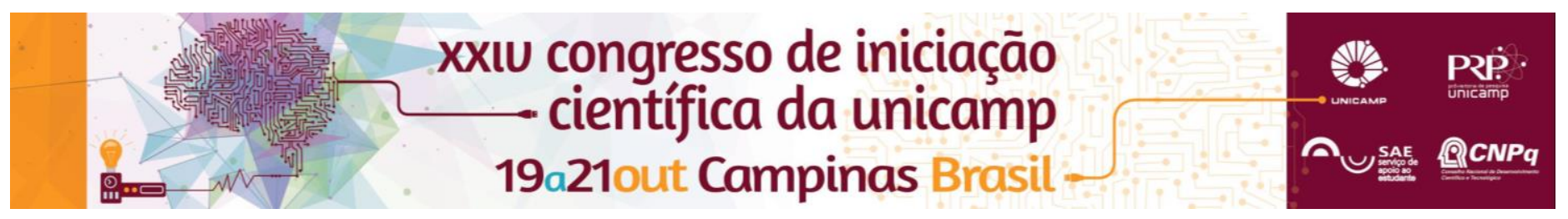

\title{
Diabetes: percepção dos diabéticos acerca da doença
}

\author{
Gustavo Henrique de Brito Santos*, Sergio Roberto de Lucca
}

\section{Resumo}

A diabetes mellitus é uma doença crônica de grande importância na saúde pública brasileira porque atinge 13 milhões de pessoas, cerca de 7\% da população. O objetivo deste estudo foi analisar a diabete tipo 1 na percepção dos próprios pacientes acerca da doença. Foram entrevistados 20 pacientes com acompanhamento regular ao ambulatório, sendo que todos concordaram em participar da pesquisa. Sete (35\%) dos entrevistados, além de diabetes também sofriam com Hipertensão que quando associada à diabetes pode ser algo devastador. Seis (30\%) pacientes apresentaram algum tipo de complicação causada pela diabetes. E apesar de $90 \%$ dos entrevistados afirmarem que conhecem a doença e suas complicações, a maioria deles apontaram dificuldades para a prática de exercício físico e dieta alimentar.

\section{Palavras-chave: \\ Diabetes; Percepção; Complicações}

\section{Introdução}

A diabetes mellitus e a hipertensão arterial sistêmica são as duas doenças crônicas não transmissíveis de maior prevalência nos países industrializados e no Brasil. E portanto, se constitui em um problema de saúde pública. Estima-se que mais de 300 milhões de pessoas possuam diabetes no mundo. O Brasil está em $4^{\circ}$ lugar na lista dos 10 países com os maiores índices da doença, com mais de 13 milhões de casos, o que representa 6,9\% da população. E esse número está crescendo. ${ }^{1}$ Diabetes é uma doença crônica caracterizada pela insuficiência de produção de insulina pelo pâncreas e são classificadas em dois tipos: diabete tipo 1, insulinodependentes e diabete tipo 2 de manifestação tardia e não necessariamente dependentes de insulina. A diabetes tipo 1 é mais grave porque na maioria das vezes aparece na infância, enquanto que na tipo 2 se manifesta a partir da meia idade. A falta de tratamento pode ocasionar severas alterações no sistema nervoso periférico e infecções em membros inferiores até a amputação, perda progressiva da capacidade visual e lesão do sistema urinário, podendo levar à insuficiência renal. $O$ objetivo deste estudo foi analisar a diabete tipo 1 na percepção dos próprios pacientes acerca da doença.

\section{Resultados e Discussão}

Foram entrevistados 20 pacientes com acompanhamento regular ao ambulatório, sendo que todos concordaram em participar da pesquisa. As entrevistas foram realizadas no saguão de espera do ambulatório de diabetes do Hospital das Clinicas da Unicamp e seguiram um roteiro com perguntas sobre o perfil biossocial dos participantes (idade, sexo, estado civil, profissão, cidade e bairro de moradia, peso e altura) e também sobre a percepção da doença e suas complicações, tratamento e dificuldades apontadas.

Entre os entrevistados a média de idade é de 37,6 anos, sendo a idade mínima de 16 anos e a idade máxima de 62 anos. Cerca de onze (55\%) dos entrevistados foram diagnosticados ainda na infância ou adolescência, mostrando que quase a metade dos pacientes entrevistados descobrem a doença muito tarde.
Cerca de $65 \%$ dos pacientes entrevistados não trabalhavam ou não possuíam uma profissão e os outros $35 \%$ recebiam algum tipo de renda.

Entre os pacientes entrevistados três pessoas estavam abaixo do peso, oito com peso normal, sete com sobrepeso e dois com obesidade. A obesidade é um fator de risco, mas o que muitos pacientes não sabem é que estar abaixo do peso recomendado pode indicar um descontrole no tratamento.

Sete $(35 \%)$ dos entrevistados, além de diabetes também sofriam com Hipertensão que quando associada à diabetes pode ser algo devastador.

Seis $(30 \%)$ pacientes apresentaram algum tipo de complicação causada pela diabetes, entre elas: furúnculos, nefropatia, retinopatia, gastroenteropatia, hipotireoidismo, problemas oftalmológicos e amputação dos pés. E quatorze $(70 \%)$ alegaram que a doença causa algum tipo de medo ou receio.

\section{Conclusões}

Apesar de $90 \%$ dos entrevistados afirmarem que conhecem a doença e suas complicações, a maioria deles apontaram dificuldades para a prática de exercício físico e dieta alimentar.

\section{Agradecimentos}

Nossos agradecimentos à equipe de saúde do ambulatório de diabetes do departamento de endocrinologia/FCM/Unicamp

\footnotetext{
1 LUCILIUS, C.; ROQUE, C. Campanha no HC alerta para prevenção do diabetes, Disponível em: http://www.hc.unicamp.br/node/779
} 